\title{
ÓLEOS ESSENCIAIS NO BRASIL: ASPECTOS GERAIS, DESENVOLVIMENTO E PERSPECTIVAS
}

\author{
Humberto R. Bizzo \\ Embrapa Agroindústria de Alimentos, 23020-470 Rio de Janeiro - RJ, Brasil \\ Ana Maria C. Hovell e Claudia M. Rezende* \\ Instituto de Química, Universidade Federal do Rio de Janeiro, 21945-970 Rio de Janeiro - RJ, Brasil
}

Recebido em 15/1/09; aceito em 16/3/09; publicado na web em 2/4/09

\begin{abstract}
BRAZILIAN ESSENTIAL OILS: GENERAL VIEW, DEVELOPMENTS AND PERSPECTIVES. Essential oils are extracted by steam distillation of plants or cold pressing of citrus fruit pericarp. They are used in food, cosmetic, personal care and pharmaceutical industries. In Brazil, oils from orange and related products contribute to near 97\% to the positive commercial performance of the sector. Predatory exploitation and the availability of new sources of raw materials, with more attracting prices, changed the paradigm. Prospective studies, sustainable use of Brazilian biodiversity, domestication of exotic species with commercial relevance, the use of breeding techniques and the development of new applications for essential oils are thematic lines, usually multidisciplinary, which have been prompting the expansion of the research on essential oils. This paper presents an analysis on essential oils balance trade from 2005 to 2008 and some historical data on research and production of essential oils in Brazil.
\end{abstract}

Keywords: essential oil; Brazilian market; historical and perspectives.

\section{INTRODUÇÃO}

Óleos essenciais (OE) são extraídos de plantas através da técnica de arraste a vapor, na grande maioria das vezes, e também pela prensagem do pericarpo de frutos cítricos, que no Brasil dominam o mercado de exportação. São compostos principalmente de mono e sesquiterpenos e de fenilpropanoides, metabólitos que conferem suas características organolépticas.

Flores, folhas, cascas, rizomas e frutos são matérias-primas para sua produção, a exemplo dos óleos essenciais de rosas, eucalipto, canela, gengibre e laranja, respectivamente. Possuem grande aplicação na perfumaria, cosmética, alimentos e como coadjuvantes em medicamentos. São empregados principalmente como aromas, fragrâncias, fixadores de fragrâncias, em composições farmacêuticas e orais e comercializados na sua forma bruta ou beneficiada, fornecendo substâncias purificadas como o limoneno, citral, citronelal, eugenol, mentol e safrol. ${ }^{1,2}$

Há inúmeros conglomerados internacionais que negociam óleos essenciais, os mais importantes empregando-os como matéria-prima para a produção de aromas e fragrâncias. Neste artigo, os OE serão focalizados como produto principal e desvinculados das grandes áreas da perfumaria, cosméticos e aromas para alimentos.

Há 300 OE de importância comercial no mundo, os 18 principais podem ser vistos na Tabela $1 .^{3}$

O Brasil tem lugar de destaque na produção de $\mathrm{OE}$, ao lado da Índia, China e Indonésia, que são considerados os 4 grandes produtores mundiais. ${ }^{4}$ A posição do Brasil deve-se aos OE de cítricos, que são subprodutos da indústria de sucos. No passado, o país teve destaque como exportador de OE de pau-rosa, sassafrás e menta. Nos dois últimos casos, passou à condição de importador.

\section{MERCADO MUNDIAL DE OE}

De acordo com a base de dados americana COMTRADE (United Nations Commodity Trade Statistics Database), os maiores consumidores de OE no mundo são os EUA (40\%), a União Européia - UE

*e-mail: crezende@iq.ufrj.br
(30\%), sendo a França o país líder em importações e o Japão (7\%), ao lado do Reino Unido, Alemanha, Suíça, Irlanda, China, Cingapura e Espanha. O mercado mundial de OE gira em torno de US\$

Tabela 1. Os 18 principais óleos essenciais no mercado mundial (adaptada da ref. 3)

\begin{tabular}{|c|c|}
\hline Óleo essencial & Espécie \\
\hline Laranja (Brasil) & Citrus sinensis (L.) Osbeck \\
\hline Menta japonesa (Índia) & $\begin{array}{l}\text { Mentha arvensis L. f. piperascens } \\
\text { Malinv. ex Holmes }\end{array}$ \\
\hline Eucalipto (tipo cineol) & $\begin{array}{l}\text { Eucalyptus globulus Labill., E. polybractea } \\
\text { R.T. Baker e Eucalyptus spp. }\end{array}$ \\
\hline Citronela & $\begin{array}{l}\text { Cymbopogon winterianus Jowitt e } C \text {. } \\
\text { nardus (L.) Rendle }\end{array}$ \\
\hline Hortelã-pimenta & Mentha $\mathrm{x}$ piperita $\mathrm{L}$. \\
\hline Limão & Citrus limon (L.) N.L. Burm. \\
\hline Eucalipto (tipo citronela) & Eucalyptus citriodora Hook. \\
\hline Cravo-da-índia & $\begin{array}{l}\text { Syzygium aromaticum (L.) Merr. e L. } \\
\text { M. Perry }\end{array}$ \\
\hline Cedro (EUA) & $\begin{array}{l}\text { Juniperus virginiana L. e J. ashei } \\
\text { Buchholz }\end{array}$ \\
\hline Lima destilada (Brasil) & $\begin{array}{l}\text { Citrus aurantifolia (Christm. \& Panz.) } \\
\text { Swingle }\end{array}$ \\
\hline Spearmint (nativa) & Mentha spicata $\mathrm{L}$. \\
\hline Cedro (China) & Chamaecyparis funebris (Endl.) Franco \\
\hline Lavandim & Lavandula intermedia Emeric ex Loisel \\
\hline Sassafrás (China) & $\begin{array}{l}\text { Cinnamomum micranthum (Hayata) } \\
\text { Hayata }\end{array}$ \\
\hline Cânfora & Cinnamomum camphora (L.) J. Presl. \\
\hline Coentro & Coriandrum sativum $\mathrm{L}$. \\
\hline Grapefruit & Citrus paradisi Macfady \\
\hline Patchouli & Pogostemon cablin (Blanco) Benth. \\
\hline
\end{tabular}


15 milhões/ano, apresentando crescimento aproximado de $11 \%$ por ano (ITC, 2005; COMTRADE, 2005). ${ }^{5,6}$

A importação de OE no ano de 2004 pela UE, a partir dos países em desenvolvimento, pode ser vista da Tabela 2. O Brasil aparece entre os principais países fornecedores dos $\mathrm{OE}$ de laranja, limão, lima e outros cítricos, contribuindo no período com 5\% do total de óleos importados e encontra-se entre os grandes exportadores internacionais.

Tabela 2. Importação de óleos essenciais pela UE, em 2004, de países em desenvolvimento (adaptada da ref. 7)

\begin{tabular}{|c|c|c|}
\hline $\mathrm{OE}$ & $\begin{array}{l}\text { Importação } \\
\text { (US\$ milhões) }\end{array}$ & País \\
\hline Laranja & 62 & $\begin{array}{l}\text { Brasil (38\%), Cuba (2\%), } \\
\text { África do Sul (1\%) }\end{array}$ \\
\hline Limão & 57 & $\begin{array}{l}\text { Argentina }(50 \%) \text {, México } \\
(4 \%) \text {, Brasil }(3 \%)\end{array}$ \\
\hline Hortelã-pimenta & 55 & Índia (12\%), China (3\%) \\
\hline Outras mentas & 38 & $\begin{array}{l}\text { Índia (22\%), China (15\%), } \\
\text { Marrocos (1\%) }\end{array}$ \\
\hline Outros cítricos & 37 & $\begin{array}{l}\text { Brasil (5\%), Cuba (5\%) } \\
\text { África do Sul (20\%) }\end{array}$ \\
\hline Lavanda & 19 & China (3\%), Geórgia (1\%) \\
\hline Lima & 18 & $\begin{array}{l}\text { México (33\%), Peru (14\%), } \\
\text { Brasil (4\%), Argentina (2\%) }\end{array}$ \\
\hline Bergamota & 15 & Costa do Marfim (4\%) \\
\hline $\begin{array}{l}\text { Cravo-da-índia, } \\
\text { melaleuca (niauli) }\end{array}$ & 15 & $\begin{array}{l}\text { Madagascar (26\%), Comores } \\
(18 \%) \text {, Maiote }(9 \%)\end{array}$ \\
\hline Gerânio & 8 & $\begin{array}{l}\text { Egito (34\%), China (24\%), } \\
\text { África do Sul ( } 2 \%)\end{array}$ \\
\hline Vetiver & 8 & $\begin{array}{l}\text { Haiti }(56 \%) \text {, Indonésia (9\%), } \\
\text { Índia }(2 \%)\end{array}$ \\
\hline Jasmim & 5 & $\begin{array}{l}\text { Egito (44\%), Índia (28\%), } \\
\text { Madagascar (1\%) }\end{array}$ \\
\hline Total & 601 & $\begin{array}{l}\text { China (6\%), Brasil (5\%), } \\
\text { Argentina (5\%), Índia (5\%) }\end{array}$ \\
\hline
\end{tabular}

No cômputo geral dos principais países fornecedores de OE para a UE neste mesmo ano, a distribuição foi: EUA (19\%), França (10\%), China (6\%), Brasil (5\%) e Reino Unido (5\%). ${ }^{7}$

As importações de OE pelos EUA, no período de 2004-2007, perfizeram um total de cerca de US\$ 9.432 milhões, de acordo com os dados da FAS (Foreign Agriculture Service) ${ }^{8}$ sendo o percentual de exportação $50 \%$ menor. Os principais exportadores de OE para os EUA, no mesmo período, foram Índia, França, Argentina, Brasil, México, Canadá e Irlanda, sendo o Brasil o quarto do ranking, contribuindo principalmente com $\mathrm{OE}$ cítricos, com destaque para o OE de laranja.

A Figura 1 mostra as importações pelos EUA, no período de 2004 a 2007. ${ }^{8}$ As exportações de OE brasileiros representaram 2\% do total importado pelos EUA. Verificou-se um crescimento suave nas exportações brasileiras, diferentemente da Índia e da Argentina, que apresentaram aumento significativo no período.

O Brasil destaca-se na produção mundial de OE, mas sofre de problemas crônicos como falta de manutenção do padrão de qualidade dos óleos, representatividade nacional e baixos investimentos governamentais no setor, que levam ao quadro estacionário observado. Recentemente, foi fundada a ABRAPOE (Associação Brasileira de

\section{IMPORTAÇÕES DE OE PELOS EUA (2004-2007)}

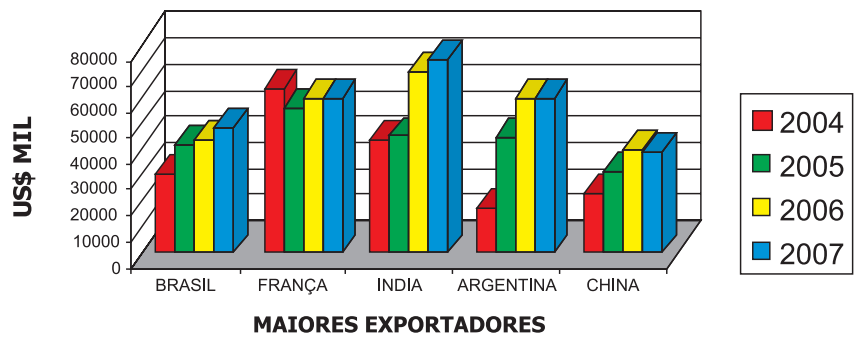

Figura 1. Importações de óleos essenciais pelos EUA no período de 2004 a 2007

Produtores de Óleos Essenciais) que busca, entre outras metas, colaborar na aproximação entre os produtores e os centros de pesquisa nacionais para agregar qualidade aos óleos através de pesquisa e estudos de padronização, fornecer dados atualizados de mercado e representar a área frente aos órgãos e programas governamentais.

Entre as indústrias produtoras de OE no Brasil, podemos citar a Raros, que segundo seu Diretor Geral, Sergio Costa Gomes Neto, produz e beneficia óleos essenciais. Os principais OE produzidos pela empresa são vetiver (24 t/ano), patchouli (12 t/ano), lemongrass (4t/ ano), palma-rosa (4 t/ano), tendo começado a produzir OE de gerânio egípcio ( 1 t/ano) em 2008. Estes óleos são beneficiados e toda a sua produção é exportada.

Outra indústria produtora de OE no Brasil, a Dierberger que, segundo o Gerente de Controle de Qualidade, Idevar Morales Passos, além de produzir, também os compra para beneficiar. Os principais OE produzidos pela empresa são mandarina (35-40 t/ano), limão siciliano (5-10 t/ano), laranja azeda (10-12 t/ano), limão taiti (3-5 t/ ano) e bergamota (pequena produção).

A Dierberger produz também, há dois anos, fragrâncias com o OE de priprioca, com características amadeiradas, devido ao crescente interesse do mercado em produtos obtidos de ativos naturais da Amazônia. A Duas Rodas Industrial, fundada em 1925, é uma das maiores produtoras de matérias-primas para a indústria de alimentos da América Latina, que beneficia e emprega OE em suas formulações. Os OE utilizados são importados principalmente da França, Inglaterra e Espanha, segundo informações de Fernanda Voltolini, do Departamento de Marketing da Duas Rodas. As matérias-primas para indústria de alimentos produzidas pela Duas Rodas são exportadas para toda a América Latina, América do Norte e países da Europa, África e Ásia.

A Ioto Internacional, cujas atividades foram iniciadas em 1999, produz somente aromas para tabaco, sempre visando o mercado de exportação. A Ioto Internacional é uma empresa de pequeno porte e a única empresa na América Latina especializada em aromas para tabaco, com volume de vendas de 900 t em 2007 e previsto para 1000 t em 2009 (apenas de aditivos para tabaco). Os OE utilizados em suas formulações são comprados de fornecedores internacionais, já com grande experiência no ramo (como, por exemplo, a Citrus \& Allied Essences, Ltd.), pois a qualidade é garantida, segundo a diretora Bianca Iodice. A importação direta do produtor de OE é complicada, já que não há como garantir a qualidade, enquanto que as grandes firmas retificam e analisam o óleo antes de vender. Por ser uma empresa brasileira, também mantém projetos de pesquisa com diferentes instituições, tentando sempre procurar soluções inovadoras e novos processos/produtos.

A seguir, o panorama da área de óleos essenciais no Brasil será apresentado com vistas à base de dados do Sistema de Análise das Informações de Comércio Exterior via Internet, no período de janeiro 
de 2005 a outubro de 2008, sendo este levantamento contextualizado num breve histórico da área de OE no Brasil.

\section{BREVE HISTÓRICO DA PESQUISA EM OE NO BRASIL}

A história da pesquisa de OE no Brasil remonta aos trabalhos de Theodor Peckolt, farmacêutico originário da Silésia alemã (atual Polônia), que chegou ao Brasil em 1847. ${ }^{9}$ Estudou e publicou vasta literatura sobre a flora brasileira (cerca de 170 trabalhos), a maioria em periódicos alemães, incluindo dados sobre rendimento e composição de óleos essenciais. ${ }^{10}$

Em 1918, o médico baiano Mario Saraiva transformou o Laboratório de Fiscalização de Defesa da Manteiga, que controlava as importações deste produto, no Instituto de Química, vinculado ao Ministério da Agricultura, Indústria e Comércio, expandindo suas atribuições. Diversificando suas áreas de atuação, a instituição passou à designação de Instituto de Química Agrícola (IQA) em 1934, sendo incorporado quatro anos depois ao Centro Nacional de Ensino e Pesquisas Agronômicas (CNPEA). Posteriormente, já em 1943, o IQA foi incorporado ao Serviço Nacional de Pesquisas Agronômicas (SNPA), do qual faziam parte também o Instituto de Óleos (IO), o Instituto de Fermentação (IF) e os Institutos Agronômicos do Norte, Nordeste, Sul e Oeste. ${ }^{11}$

Embora trabalhos isolados sobre o óleo de pau-rosa e sobre "Essencias vegetaes, naturaes e artificiaes do Brasil" tenham sido publicados por profissionais ligados a empresas produtoras na Revista de Química Industrial, ${ }^{12}$ o estudo sistemático das fontes de OE no país foi iniciado no IO, particularmente para o óleo de sassafrás, ${ }^{13} \mathrm{e}$ no IQA, para o óleo de pau-rosa. ${ }^{14}$

Os estudos de fitoquímica foram expandidos e diversificados no IQA na década de 50 pelo grupo de pesquisa que reunia os professores Walter Baptist Mors, Otto Richard Gottlieb, Benjamin Gilbert e Mauro Taveira Magalhães, sendo o último responsável pela implementação da área de OE no IQA. Além da equipe de pesquisadores, o IQA possuía um moderníssimo espectrofotômetro de infravermelho de feixe duplo e uma excepcional biblioteca, que além de livros mantinha assinaturas dos principais periódicos da área. ${ }^{11}$

Na mesma época, no Instituto Agronômico de Campinas (IAC), foram conduzidos trabalhos de pesquisa com plantas aromáticas, culminando com o lançamento da cultivar de menta IAC-701, tendo levado o Brasil à liderança no fornecimento mundial de mentol no final da década seguinte. ${ }^{15}$

O IQA foi extinto em 1962, numa re-estruturação do Ministério da Agricultura. Os professores W. Mors e B. Gilbert se transferiram para a Universidade Federal do Rio de Janeiro, fundando o Centro de Pesquisas de Produtos Naturais (hoje Núcleo de Pesquisas de Produtos Naturais) em 1963. ${ }^{16}$ O professor O. Gottlieb esteve na Universidade de Brasília, Universidade Federal Rural do Rio de Janeiro, Instituto Nacional de Pesquisas da Amazônia, Universidade de São Paulo e Fundação Oswaldo Cruz, entre outras instituições. Nessa caminhada propagou o estudo da fitoquímica, através de suas pesquisas e da formação de recursos humanos, tendo sido o orientador de diversos líderes de grupos em produtos naturais espalhados pelo país. ${ }^{17}$

Do que restou do IQA após sua extinção criou-se a Divisão de Tecnologia Agrícola e Alimentar, subordinada ao Departamento Nacional de Pesquisas e Experimentação Agropecuárias (DNPEA), ao qual também foram subordinados o Instituto de Óleos e o Instituto de Fermentação, embora estes tenham tido sua estrutura administrativa preservada. Depois de diversas mudanças de nomes (Divisão de Tecnologia Alimentar, Centro de Tecnologia Alimentar), em 1971, com a extinção do IO e do IF, a instituição recebeu a designação de Centro de Tecnologia Agrícola e Alimentar (CTAA), e seria incorporada, dois anos depois, à recém-fundada Empresa Brasileira de Pesquisa
Agropecuária (EMBRAPA), mudando de nome mais uma vez para Centro Nacional de Tecnologia Agroindustrial e de Alimentos, ou Embrapa Agroindústria de Alimentos. ${ }^{18}$

De 1918 a 1984, o IQA e parte de sua herança permaneceram nas instalações originais ao lado do Jardim Botânico do Rio de Janeiro tendo sido transferidos, já com o nome de Embrapa Agroindústria de Alimentos, para o remoto bairro de Guaratiba, também no Rio de Janeiro, onde ainda podem ser encontrados alguns equipamentos, peças de porcelana e, a relíquia mais importante, a biblioteca do IQA. Também resta o livro de visitas, no qual uma rápida folheada permite vislumbrar as assinaturas de Carl Djerassi, Ernest Wenkert, César Lattes e Marie Curie. Embora extinto em 1962, as sementes geradas no IQA foram lançadas em terra fértil, germinaram, cresceram, multiplicaram-se e hoje estão nas principais Universidades e Centros de Pesquisa do país.

Dos muitos pesquisadores ativos hoje na área de óleos essenciais, é imperioso mencionar dois, por suas destacadas contribuições: os professores José Guilherme Soares Maia e Afrânio Aragão Craveiro. Além de suas atuações na formação de recursos humanos - o professor Maia no INPA, Museu Paraense Emilio Goeldi e na UFPA; o professor Craveiro na UFC - sua obra científica representa valiosa contribuição ao conhecimento e aproveitamento da flora nativa da Amazônia ${ }^{19}$ e do Nordeste, ${ }^{20}$ respectivamente. Em tempo: os dois foram alunos do professor O. Gottlieb.

\section{ÓLEOS ESSENCIAIS NO SISTEMA ALICE-WEB}

O Sistema ALICE-Web de busca na internet é gratuito e desenvolvido pela Secretaria de Comércio Exterior (SECEX) do Ministério do Desenvolvimento, Indústria e Comércio Exterior (MDIC). Fornece informações atualizadas mensalmente sobre os dados estatísticos das exportações e importações brasileiras, como apoio do Sistema Integrado de Comércio Exterior (SISCOMEX), que administra o comércio exterior brasileiro. ${ }^{21}$

A busca pela palavra-chave óleo essencial no sistema ALICEWeb, no período de janeiro de 2005 a outubro de 2008, mostra 27 produtos entre os quais 7 óleos essenciais de cítricos (laranja, bergamota, petit grain de laranja, limão, lima, outros de lima e outros cítricos), 4 óleos de mentas (hortelã-pimenta - Mentha piperita, menta japonesa - $M$. arvensis, menta spearmint - $M$. viridis e óleos de outras mentas), 4 óleos de flores (gerânio, jasmim, alfazema ou lavanda e outros óleos de lavanda), 4 óleos de madeira (pau-rosa, pau-santo Bulnesia sarmientol, cabreúva e cedro) e o restante de folhas, como citronela, lemongrass ou capim-limão, palmarosa e o óleo de eucalipto, além do vetiver e "outros óleos de vetiver" e óleo da semente de coriandro (coentro), perfazendo 26 itens. $\mathrm{O} 27^{\circ}$ item inclui outros óleos essenciais, sem descrição detalhada dos produtos.

A importação destes 27 itens, no período de janeiro de 2005 a outubro de 2008 , foi de 8.938 t, sendo $42 \%$ de mentas, $29 \%$ de cítricos, $15 \%$ de óleos de folhas, $4 \%$ de óleos de flores, $2 \%$ de óleos de madeiras e $22 \%$ de outros OE.

Quanto à exportação no período, o montante foi de 119.772 t, havendo domínio total dos OE oriundos da indústria cítrica, representando acima de $95 \%$ destas exportações. O principal responsável por este quadro é o OE de laranja.

Em relação à balança comercial no mesmo período, foram exportados US\$ (FOB) 309,5 milhões contra US\$ (FOB) 171,2 milhões importados, sendo que os óleos oriundos de cítricos responderam por 93\% das exportações financeiras.

O limoneno é o principal produto obtido do beneficiamento de OE no Brasil. No período, foram exportados $427 \mathrm{t}$ de limoneno, $70 \%$ para a UE. Suas principais aplicações são para produtos de limpeza e como solvente. 


\section{ÓLEOS ESSENCIAIS DE CÍTRICOS}

As frutas cítricas são as mais cultivadas no mundo, sendo a laranja a principal delas. A produção de laranjas e a industrialização do suco estão concentradas em quatro países, sendo o Brasil o primeiro deles, respondendo por um terço da produção mundial da fruta e quase $50 \%$ do suco fabricado. Aproximadamente $70 \%$ é processado e $30 \%$ vai para o consumo interno.

O OE de laranja, extraído do pericarpo do fruto, é um subproduto da indústria do suco. Derivados de OE de laranja são usados em perfumaria, sabonetes e na área farmacêutica em geral, além de materiais de limpeza, em balas e bebidas. O rendimento máximo de extração de óleos cítricos é de $0,4 \%$, ou seja, para cada tonelada de fruta processada são obtidos $4 \mathrm{~kg}$ de óleo. ${ }^{22}$

No período de janeiro de 2005 a outubro de 2008, a exportação de OE de cítricos pelo Brasil foi de 287.759 t. O OE de laranja foi responsável por $86 \%$ das exportações, o de limão $8 \%$, os de lima $3 \%$, outros cítricos $2 \%$ (como toranja, cidra, tangerina, entre outros) e os de bergamota e petit grain por aproximadamente $1 \%$, em conjunto. O valor aproximado do óleo de laranja no período foi de US\$2/kg. O principal estado produtor é São Paulo e a norma ISO 3140:2005 determina os padrões de qualidade a serem seguidos para o óleo de laranja (Citrus cinensis L. Osbeck). ${ }^{23,24}$

Segundo publicação da revista Química e Derivados, os óleos de bergamota, limão, mandarina, tangerina e laranja estão entre as composições cítricas (blends) mais vendidas no mundo para a perfumaria. Atualmente, a Symrise, criada em 2002 com a fusão de duas grandes empresas concorrentes em fragrâncias, aromas e químicos, a Dragoco e a Haarmann \& Reimer, ingressou fortemente no setor de biotecnologia e ativos naturais para fins cosméticos e já responde por $16 \%$ de participação no mercado brasileiro. ${ }^{25}$

Segundo dados da EUROSTAT, o Brasil exportou para a comunidade européia 12.526 t de óleo de laranja em 2006, sendo 43\% para a Holanda, $20 \%$ para a Alemanha e $19 \%$ para o Reino Unido. ${ }^{7}$

O principal exportador de OE de laranja para os EUA é o Brasil, seguido da Itália, de acordo com o órgão americano FAS. No período de janeiro de 2005 a outubro de 2008, foram exportados 38.024 t de óleo de laranja. Pelo sistema ALICE-Web, as exportações de óleos de laranja para os EUA neste período representaram $35 \%$ das exportações brasileiras de OE e para a UE, $46 \%$ do total.

O óleo essencial de petit grain (obtido das folhas da laranja $C$. aurantium var. amara por arraste a vapor) também contribuiu para o favorecimento da balança comercial, assim como os óleos de lima. Os óleos de limão e bergamota são deficitários na balança comercial, embora a quantidade de óleo de limão exportada tenha sido maior que a importada no período $(1.762 \times 1.598 \mathrm{t})$. Isto pode estar relacionado à qualidade distinta dos óleos e, consequentemente, com a relação preço/kg dos produtos.

\section{ÓLEOS ESSENCIAIS DE EUCALIPTO}

Estes óleos são classificados em 3 grupos de acordo com sua aplicação, que são para fins industriais, perfumaria ou medicinal. Em torno de 600 espécies de eucalipto já foram descritas, das quais 20 são citadas para uso comercial. ${ }^{26}$ Todas as espécies de eucalipto são ricas em compostos monoterpênicos, sendo as espécies com fins medicinais ricas em cineol (mínimo de 70\%), enquanto aquelas de aplicação industrial destacam-se pelo teor de felandreno e piperitona e as de uso na perfumaria são ricas em citronelal, citral ou acetato de geranila. No Brasil, a principal espécie produtora de óleo medicinal é a Eucalyptus globulus, enquanto que a espécie produtora de óleo para a perfumaria é a $E$. citriodora, rica em citronelal, ao lado de $E$. staigeriana, rica em citral. Não há produção destacada no país em espécies produtoras de óleos para fins industriais. ${ }^{27}$

As espécies de eucalipto foram introduzidas no Brasil para fins de aproveitamento da madeira, sendo muito utilizadas para a indústria de celulose, serraria, postes, mourões de cercas e produção de carvão vegetal, com destaque para E. citriodora. Na produção de OE, para cada $1000 \mathrm{~kg}$ de massa foliar, são obtidos cerca de 10 a $16 \mathrm{~kg}$ de óleo ( 1,0 a $1,6 \%$ de rendimento) e entre 65 a $85 \%$ de citronelal. E. globulus fornece $\mathrm{OE}$ em rendimento superior $(1,5$ a $5,5 \%)$ dependendo da subespécie, enquanto que E. staigeriana apresenta rendimento médio de $1,4 \% .^{27}$

As exportações brasileiras dos OE de eucalipto, no período de 2005-2008, somaram US\$ 9,6 milhões relativos a 1.237 t, sendo $66 \%$ do estado de São Paulo e 33\% de Minas Gerais. O principal importador foi a UE (45\%), especificamente Espanha (24\%), Reino Unido (13\%) e Suíça (10\%), seguido dos EUA (33\%).

\section{ÓLEO ESSENCIAL DE PAU-ROSA}

O Brasil é o único fornecedor de OE de pau-rosa no mundo. Da espécie Aniba roseaodora var amazonica Ducke extrai-se o óleo da madeira por arraste a vapor, rico em linalol. ${ }^{28} \mathrm{~A}$ história deste óleo confunde-se com a exploração indiscriminada das espécies florestais da Amazônia. Foi o primeiro OE extraído em larga escala e exportado pelo Brasil. Sua exploração começou em 1925, inicialmente no Pará e depois no Amazonas. Em 1927, a produção nacional atingiu 200 t, não havendo mercado para absorver o volume produzido. ${ }^{29} \mathrm{~A}$ preocupação com a exploração predatória já era manifestada em 1933, apenas alguns anos após o início da extração do óleo. ${ }^{30}$ Decretos governamentais estabelecendo limites de produção e reflorestamento foram emitidos e grosseiramente ignorados. O pico de produção ocorreu nos anos 60 , quando cerca de $500 \mathrm{t}$ anuais eram exportadas. Estas foram progressivamente reduzidas com a entrada no mercado do linalol sintético, do óleo essencial das folhas de Ho (Cinnamomum camphora), rico em linalol, e da própria escassez do pau-rosa, que obrigou os produtores a penetrar cada vez mais fundo na floresta para obter a matéria-prima, com o consequente aumento do custo de produção. ${ }^{28}$

Segundo dados do ALICE-Web, o OE de pau-rosa é vendido de US\$ 50 a 100/kg e, no período de janeiro de 2005 a outubro de 2008, foram exportados $121 \mathrm{t}$, perfazendo US\$ 9,4 milhões, ou seja, um valor médio de US\$77/kg. O principal estado exportador foi o Amazonas (80\%). O óleo foi exportado principalmente para os EUA $(58 \%)$ e a UE $(41 \%)$. Atualmente, há projetos de plantio racional de pau-rosa, como o desenvolvido em Santarém, fruto da parceria entre a Pematec, o INPA, a Emater e a Unicamp, buscando uma nova técnica de extração a partir de podas periódicas de galhos e folhas, dos quais o óleo também pode ser obtido. ${ }^{31}$

\section{ÓLEOS ESSENCIAIS DE VETIVER, CITRONELA E CAPIM-LIMÃO}

Vetiver (Vetiveria zizanioides (L.) Nash), citronela (Cymbopogon winterianus Jowitt) e capim-limão (Cymbopogon citratus (DC ex Nees) Stapf), todos pertencentes à família Poaceae, já eram cultivados no país nos anos 50. No caso do vetiver, houve problemas no momento das primeiras colheitas, pois o solo no qual as plantas foram cultivadas era muito compacto (na região de Cambuí, interior de São Paulo), e as raízes (onde se acumula a maior parte do OE) se romperam, permanecendo sob a terra, havendo necessidade de revolver o solo para sua remoção, aumentando a demanda de mão-de-obra e reduzindo o rendimento do óleo essencial. A citronela, plantada também no interior de São Paulo, carecia de solos mais férteis, de modo a se obter mais de uma colheita anual. Embora o clima fosse 
favorável, a safra de 1955 foi completamente perdida em função de uma geada no local. Estes óleos tiveram sua produção mantida em pequena escala, principalmente para o abastecimento do mercado de especialidades químicas, que se desenvolveu com a instalação de várias casas de aromas no país ao longo das décadas de 50 e 60 . A empresa Dierberger foi pioneira na introdução e cultivo de plantas aromáticas no país, como a palmarosa (Cymbopogon martini (Roxb.) J. F. Watson). ${ }^{32}$

Os óleos essenciais de vetiver, citronela e capim-limão apresentaram balança comercial deficitária no período de 2005 a 2008. Há uma movimentação importante para o aumento do cultivo destas espécies no país, mas ainda sem reflexos no quadro de exportação.

Neste período, foram exportados 13,9 t de óleos de vetiver num montante de US\$1,0 milhão (US\$73/kg), exclusivamente do estado do Rio Grande do Norte e para os países da UE. ${ }^{33}$ Neste mesmo período, o país importou US\$1,8 milhão relativo a $11 \mathrm{t}$ de óleo, principalmente do Haiti. Foram exportados 1,2 t de vetiverol, um dos principais constituintes obtidos do OE do vetiver, perfazendo US\$ 1.636 (US\$ 1,4/kg), contra uma importação de US\$ 726 mil relativos a $23,4 \mathrm{t}$ (US\$31/kg).

Quanto à citronela, foram exportados US\$ 89,7 mil relativos a 5,7 $\mathrm{t}$ (US\$ 15/kg), oriundos principalmente dos estados do Rio Grande do Sul e São Paulo, contra uma importação de US\$ 623,4 mil relativos a 68,2 t. Em relação ao capim-limão, foram exportados US\$150,5 mil relativos a 9,6 t, oriundos principalmente do estado de São Paulo e para a UE (Alemanha, Reino Unido e Espanha). A importação foi de US\$ 150 mil correspondentes a 6,8 t.

\section{ÓLEO ESSENCIAL DE SASSAFRÁS}

O sassafrás, Sassafras albidum (Nutt) Nees (Lauraceae), é uma árvore nativa da região que se estende do Maine à Flórida e da Costa Atlântica até o Mississipi, nos EUA. Infusões de suas cascas e raízes têm sido usadas desde os tempos coloniais como sudorífero. Há cerca de 80 anos, o óleo essencial foi usado como aromatizante na indústria de bebidas e como matéria-prima para a síntese de piperonal, importante insumo para a indústria de perfumaria. ${ }^{34}$ Os usos alimentícios foram descontinuados com a descoberta dos efeitos hepatotóxicos e carcinogênicos do safrol, constituinte majoritário do óleo (80-85\%). ${ }^{35}$ Além do piperonal, o safrol é usado como matéria-prima para a síntese de butóxido de piperonila, importante agente sinergístico para inseticidas à base de piretroides. ${ }^{28}$

Em meados do século XX, o Japão passou a comercializar um óleo rico em safrol, extraído de variedades de Cinnamomum camphora. Com preços mais vantajosos, houve domínio do mercado norteamericano e retração na produção dos EUA. Tal fato iria mudar com a eclosão da guerra entre os Estados Unidos e o Japão, e a consequente interrupção do fornecimento de óleo oriundo da Ásia. ${ }^{36}$

Entre 1938 e 1940, iniciou-se no Brasil a produção do óleo de sassafrás, no município de Rio do Sul, em Santa Catarina. ${ }^{37} \mathrm{Na}$ década de 40 , chegou-se a produzir até 580 t do produto. ${ }^{38} \mathrm{~A}$ distinção entre $S$. albidum (sassafrás norte-americano) e $O$. odorifera (sassafrás brasileiro) foi bem estabelecida com estudos de anatomia vegetal. ${ }^{39}$ Houve controvérsias quanto à origem do $\mathrm{OE}$ de sassafrás brasileiro, já que aparentemente ele era extraído a partir de Ocotea odorifera (Vell.) Rohwer (syn Ocotea pretiosa (Nees) Mez) e de Aniba canelilla (H.B.K.) Mez, entre outras espécies de Mespilodaphne e Ocotea.$^{40}$ O. odorifera, conhecida popularmente como canela-sassafrás, sassafrás, canelacheirosa e louro-cheiroso, é uma árvore nativa da Mata Atlântica e do Planalto Meridional, com ocorrência do Sul da Bahia até o Rio Grande do Sul. A. canelilla, por sua vez, é nativa da região amazônica. ${ }^{41}$

Entre os aspectos que dificultaram a classificação das espécies estava o fato de que as árvores originárias de Santa Catarina (e arredo- res) produziam um óleo rico em safrol, enquanto que em exemplares de Minas Gerais e outras localidades, o componente majoritário era o metileugenol. ${ }^{42}$ Outro fator estava associado ao aroma de canela percebido nos óleos de populações de Minas e ausente nas de Santa Catarina. Este aroma era devido à presença de 1-nitro-2-feniletano nos exemplares de Minas Gerais e sua ausência nas árvores de Santa Catarina. Foi a primeira descrição de uma substância nitrada presente em óleos essenciais, embora nitro-derivados sintéticos já fossem usados em perfumaria desde fins do século XIX ${ }^{43}$ Posteriormente, o 1-nitro-2-feniletano foi identificado como o componente majoritário no $\mathrm{OE}$ de $A$. canelilla, o que também contribuiu para a confusão desta espécie com exemplares de $O$. odorifera de Minas Gerais.

No período pós-guerra, o Brasil tornou-se o principal fornecedor mundial de óleo de sassafrás, e assim permaneceu até o início da década de $1990,{ }^{44}$ quando se iniciou uma rotina de importação crescente em óleo rico em safrol, principalmente da China. ${ }^{21}$

A partir de 1996, o OE de sassafrás teve sua classificação (NCM, Nomenclatura Comum do Mercosul) alterada, indo fazer parte de “Outros óleos essenciais" (NCM 3301.29.90). Desse modo não foi possível o monitoramento individual desta mercadoria.

Dentre os fatores que podem ser atribuídos ao fim da produção brasileira de óleo de sassafrás estão o baixo preço no mercado internacional (cerca de US\$4/kg), a concorrência do óleo rico em safrol de C. camphora chinês e o modelo de exploração predatória praticado contra a população de $O$. odorifera, para o qual foram ignorados os alertas sobre o provável desaparecimento da espécie, já registrados em $1945 .{ }^{38}$

Vários autores mencionam a existência de um decreto presidencial proibindo o corte de exemplares de $O$. odorifera, e em alguns artigos este decreto é identificado como de número 1557, do ano de 1991, publicado no Diário Oficial da União em 25 de setembro de $1991 .{ }^{45}$ Embora diversas fontes tenham sido consultadas, inclusive as bases de legislação do Senado Federal, não foi possível encontrar tal decreto. Encontrou-se, pelo contrário, uma portaria estabelecendo um convênio para redução do ICMS sobre o óleo de sassafrás produzido em Santa Catarina e Paraná, como forma de estimular sua produção. A portaria foi prorrogada anualmente até $1995 .{ }^{46}$

Cabe ainda mencionar uma portaria do IBAMA que apresenta uma relação de espécies nativas da flora ameaçadas de extinção, publicada em 1992, na qual consta $O$. odorifera (syn $O$. pretiosa). Esta relação foi recentemente revista e, infelizmente, aumentada. A canela-sassafrás continua listada como espécie ameaçada. ${ }^{47} \mathrm{Mesmo}$ este documento não impediu o corte legal, realizado com autorização do próprio IBAMA e da Secretaria de Meio Ambiente de Santa Catarina. Dados sobre o corte de árvores de O. odorifera ao longo da década de 1990 foram publicados. ${ }^{48}$

\section{ÓLEO ESSENCIAL DE MENTA}

Embora sejam registradas movimentações de diferentes tipos de óleo de menta no sistema $A L I C E$-Web, a mais significativa em volume e valor está associada ao OE de Mentha arvensis (menta japonesa). ${ }^{21}$ Esta cultura foi introduzida no Brasil por imigrantes japoneses e se estabeleceu em São Paulo e no Paraná, ainda nos anos $30 .{ }^{49}$ Com a Segunda Guerra Mundial e a interrupção no fornecimento de mentol da Ásia, parte da demanda passou a ser suprida pelo Brasil. Em 1943, a produção brasileira atingiu $80 \mathrm{t}$, enquanto que nos primeiros anos da década de 50 a produção média foi de 300 t/ano, com uma exportação de mentol de cerca de 150 t/ano para o mesmo período. ${ }^{15}$ Além do mentol, o óleo desmentolado também era exportado. Este produto ainda contém de 35 a $50 \%$ de mentol residual em sua composição. ${ }^{49}$ Estudos de seleção realizados no IAC levaram ao desenvolvimento da variedade IAC-701 (originalmente chamada de MA-701), com melhor rendimento em óleo essencial. ${ }^{32}$ 
O máximo da produção brasileira foi atingido em 1973, com 6.300 t de óleo bruto. ${ }^{15}$ Neste período, o Brasil foi o maior produtor mundial deste OE. É interessante observar que a produção de óleo no Paraguai foi gradativamente aumentando com o declínio da produção brasileira, pois a própria cultura da menta migrou de um país para o outro. Em função do manejo deficiente, verificou-se o esgotamento do solo após 4 ou 5 anos de cultivo. A prática associada a esta cultura foi abandonar a área esgotada e efetuar o plantio em uma nova região, via de regra após a remoção de floresta nativa. Como consequência, o Brasil passou a importar mentol e o óleo de menta bruto, este último da Índia. ${ }^{15}$ Somente a importação de mentol tem contribuído negativamente na balança comercial brasileira em cerca de 10 milhões de dólares por ano, nos últimos 4 anos..$^{21}$ No período de 2005 a outubro de 2008, as importações de OE de mentas contabilizaram US\$ 52.718 mil relativos a $3.391 \mathrm{t}$, sendo $76 \%$ de $\mathrm{OE}$ de $M$. arvensis, contra uma exportação de 305 t. $^{21}$

\section{ASCENSÃO E QUEDA DA PRODUÇÃO DE OE NO BRASIL}

O desenvolvimento da indústria de OE no Brasil foi impulsionado, num primeiro momento, pela escassez de matérias-primas durante e logo após a Segunda Guerra Mundial. A China, grande fornecedora do período antecedente à guerra, permaneceu em conflito interno após 1945, retardando a retomada das exportações de óleo. Neste cenário, floresceram as exportações de óleo de sassafrás, pau-rosa, menta e cítricos. Estes últimos como subprodutos da indústria de suco.

Já na segunda metade dos anos 50 e início da década seguinte, diversas empresas produtoras de especialidades químicas e indústrias de alimentos se instalaram no Brasil, incrementando a demanda interna por óleos. O país passava por um processo de industrialização. É neste período que certas empresas produtoras de óleo tomam a iniciativa de introduzir espécies aromáticas no país. ${ }^{32}$

Embora diversos estudos fitoquímicos fossem conduzidos em instituições como o IQA, havia carência de investigação agronômica. Este quadro foi revertido, para o caso da cultura de $M$. arvensis, com os trabalhos do IAC. Já em relação aos produtos de extrativismo, como pau-rosa e sassafrás, pouco foi feito para remediar a exploração predatória em andamento.

Com a normalização e incremento da produção chinesa, a expansão da produção para outros países, como Vietnam e Índia, houve aumento na oferta de $\mathrm{OE}$, e a preços mais competitivos. Esses fatores, aliados à falta de políticas nacionais de estímulo à produção de OE, contribuíram para a redução drástica na oferta de óleos brasileiros.

No caso específico do pau-rosa, a disponibilidade de linalol sintético a preços muito baixos limitou o mercado deste óleo à perfumaria fina, cuja demanda é reduzida. ${ }^{28}$

Os óleos de cítricos permaneceram imunes pois, como já mencionado, são subprodutos da indústria de suco, bem estabelecida no Brasil e com foco na exportação.

\section{PERSPECTIVAS}

O público tem manifestado crescente interesse sobre os processos de obtenção das matérias-primas dos produtos que consome. Apelos de políticas de preservação ambiental são instrumentos de marketing muito eficientes, particularmente no mercado europeu. Esta é uma ótima oportunidade para o desenvolvimento de processos sustentáveis de exploração da biodiversidade. $\mathrm{O}$ uso de fontes renováveis para a produção de $\mathrm{OE}$ toma lugar de destaque.

Uma extensa análise do potencial de fontes alternativas de OE foi realizada pelo grupo do professor Gottlieb ao longo dos anos $1970 .{ }^{50}$
Estes trabalhos foram continuados mais tarde por pesquisadores da Universidade do Pará, liderados pelo professor Maia. ${ }^{51}$

A eventual redução na oferta de safrol é uma das ameaças para a indústria de inseticidas piretroides e a descoberta de fontes sustentáveis para a produção desta matéria-prima é extremamente relevante, principalmente considerando-se a tendência de aumento de consumo de butóxido de piperonila. ${ }^{28,52}$ Os estudos relativos às novas fontes de safrol a partir de espécies de Piper da Amazônia são bem promissores. ${ }^{28,44}$ Das folhas de $P$. hispidinervum obtém-se um óleo essencial com teores acima de $90 \%$ de safrol, mais rico neste constituinte que o próprio óleo de sassafrás. Conhecida a fonte, tornou-se necessário desenvolver o seu cultivo. A planta tem porte arbustivo e bom rendimento em óleo. Estudos de manejo foram realizados por pesquisadores da Embrapa nos anos $90 .{ }^{53}$ Outra espécie relevante é P. callosum, sob estudo por pesquisadores da UFPA. ${ }^{44}$

A Embrapa Recursos Genéticos e Biotecnologia introduziu recentemente 29 variedades de menta no país, cujo desenvolvimento está sendo avaliado em três biomas distintos. Alguns resultados preliminares já foram publicados ${ }^{54}$ Experimentos agronômicos e, principalmente, o estabelecimento de práticas de manejo são necessárias para que as espécies introduzidas possam ser cultivadas em escala comercial.

A seleção de matrizes, a irrigação e a mecanização da cultura são práticas que têm sido aplicadas com sucesso no Nordeste do país para a produção de óleos essenciais.

Estes exemplos demonstram que a produção de óleos essenciais no Brasil é não somente viável, mas rentável. É importante ressaltar que, além dos incentivos governamentais, necessários, mas não suficientes, a formalização de parcerias de Centros de Pesquisa e Universidades com a Iniciativa Privada é fundamental para que técnicas modernas de cultivo, seleção e melhoramento de plantas sejam desenvolvidas e aplicadas, de modo a se obter produtos com qualidade e preço para disputar o mercado internacional.

\section{AGRADECIMENTOS}

À Dra R. C. Lago, da Embrapa Agroindústria de Alimentos e ao Dr. R. Salvi, da Mane do Brasil Ind. Com. Ltda, pelas valiosas contribuições na elaboração do manuscrito.

\section{REFERÊNCIAS}

1. Silva-Santos, A.; Antunes, A. M. S.; Bizzo, H. R.; d'Avila, L. A.; Rev. Bras. Pl. Med. 2006, 8, 14.

2. Craveiro, A. A.; Queiroz, D. C.; Quim. Nova 1993, 16, 224.

3. Lawrence, B. M. Em New crops; Janick, J.; Simon. J. E., eds.; Wiley: New York, 1993, p. 620.

4. http://answers.google.com/answers/threadview/id/ 757342. html, acessada em Dezembro 2008.

5. http://www.intracen.org/tradstat/sitc3-3d/ip551.htm, acessada em Dezembro 2008.

6. http://data.un.org /Data.aspx? $\mathrm{d}=$ ComTrade $\& \mathrm{f}=\_11$ Code $\% 3 \mathrm{a} 34$, acessada em Dezembro 2008.

7. http://epp.eurostat.ec.europa.eu/portal, acessada em Dezembro 2008.

8. http://www.fas.usda.gov/ustrade/USTIMFAS.asp, acessada em Dezembro 2008.

9. Pinto, A. C.; Silva, D. H. S.; Bolzani, V. S.; Lopes, N. P.; Epifanio, R. A.; Quim. Nova 2002, 25, Suplemento 1, 45.

10. http://www.dichistoriasaude.coc.fiocruz.br/iah/P/verbetes/peckteo.htm, acessada em Dezembro 2008; Chemisches Centrall-Blatt 1896, band II, 1206.

11. Faria, L. R.; Hist. Ciênc. Saúde 1997, 4, 51.

12. Leitão, E. L.; Rev. Chim. Ind. 1938, 236; Hufenuessler, R.; Rev. Chim. Ind. 1938, 24. 
13. Machado, R. D.; Bol. Div. Inst. Óleos, 1945, 21.

14. Gottlieb, O. R.; Rev. Quím. Ind. 1957, 195.

15. Hopp, R.; Lawrence, B. M. Em The Genus Mentha; Lawrence, B. M., ed.; CRC Press: Boca Raton, 2007, cap. 10.

16. Faria, L. R.; Hist. Ciênc. Saúde 2007, 14, 347.

17. http://lattes.cnpq.br/8174445528014427, acessado em Dezembro 2008.

18. Lago, R. C. A.; comunicação pessoal.

19. Maia, J. G. S.; Zoghbi, M. G. B.; Andrade, E. H. A.; Plantas Aromáticas na Amazônia e seus Óleos Essenciais, Belém: Museu Paraense Emílio Goeldi, 2001; Zoghbi, M. G. B.; Andrade, E. H. A.; Maia, J. G. S.; Aroma de Flores na Amazônia, Belém: Museu Paraense Emílio Goeldi, 2001.

20. Craveiro, A. A.; Fernandes, A. G.; Andrade, C. H. S.; Matos, F. J. A.; Alencar, J. W.; Machado, M. I. L.; Óleos Essenciais de Plantas do Nordeste, Editora da UFC: Fortaleza, 1981.

21. http://aliceweb.desenvolvimento.gov.br/, acessada em Dezembro 2008.

22. Silva-Santos, A.; Antunes, A. M. S.; Bizzo, H. R.; d'Avila, L. A.; Rev. Bras. Pl. Med. 2006, 8, 8; Silva-Santos, A.; Análise Técnica, Econômica e de Tendências da Indústria Brasileira de Óleos Essenciais, Papel Virtual: Rio de Janeiro, 2002.

23. http://www.abecitrus.com.br/, acessada em Dezembro 2008.

24. http://www.iso.ch/iso/iso_catalogue/catalogue_tc/catalogue_detail.htm? csnumber $=37542$, acessada em Dezembro 2008.

25. de Moraes, R.; Quim. Deriv. 2007, 466.

26. Doran, J. C.; Em Eucalyptus leaf oil: use, chemistry, distillation and marketing; Boland, D. J.; Brophy, J. J.; House, A. P. N., eds.; Inkata: Melbourne, 1991, p.11.

27. Vitti, A. M. S.; Brito, J. O.; ESALQ, Documentos Florestais 2003, 17, 1.

28. Coppen, J. J. W.; Flavours and Fragrances of Plant Origin, FAO: Roma, 1995.

29. Azeredo, O. B.; Bol. Inst. Óleos 1958, 137.

30. Freise, F. W.; Perf. Essent. Oil Rec. 1933, 24, 307.

31. http://www.iac.sp.gov.br/sboe2005/laurobarata.pdf, acessada em Dezembro 2008.

32. Guenther, E.; Ind. Parfum. 1956, 11, 415.

33. http://www.rarosessentialoils.com/, acessada em Dezembro 2008.

34. Guenther, E.; The Essential Oils, D. Van Nostrand Company Inc: New York, 1950, vol. IV.

35. Enomoto, M. Em Bioactive Molecules; Irono, I., ed.; Elsevier: New York, 1987, vol. II, p. 139-159.
36. Mollan, T. R. M.; Perf. Essent. Oil Rec. 1961, 52, 284.

37. Araujo, P. A. M.; Bol. Inst. Óleos 1945, 31.

38. Machado, R. D.; Bol. Inst. Óleos 1945, 21.

39. Mattos Filho, A.; Bol. Inst. Óleos 1958, 9.

40. Vattimo, I.; Bol. Inst. Óleos 1958, 117.

41. Lorenzi, H.; Matos, F. J. A.; Plantas Medicinais no Brasil: nativas e exóticas, Instituto Plantarum: Nova Odessa, 2002.

42. Mors, W. B.; Magalhães, M. T.; Gottlieb, O. R.; Perf. Essent. Oil Rec. 1959, 50, 26.

43. Gottlieb, O. R.; Magalhães, M. T.; Perf. Essent. Oil Rec. 1960, 51, 18.

44. Maia, J. G.; Green, C. L.; Milchard, M. J.; Perf. Flavor. 1993, 18, 19.

45. Pimentel, F. A.; Pereira, J. B. M.; Oliveira, M. N.; Boletim de Pesquisa, Rio Branco: Embrapa Acre, 2001, n. 20; Nunes, J. D.; Dissertação de Mestrado, Universidade Federal de Lavras, Brasil, 2004, p. 8; Bergo, C. L.; Mendonça, H. A.; Silva, M. R.; Acta Amaz. 2005, 35, 111; referência 41.

46. Convênio ICMS 51/91, de 26 de setembro de 1991, publicado no Diário Oficial da União em 30 de setembro de 1991, ratificação nacional publicada no Diário Oficial da União em 17 de outubro de 1991; prorrogado até 31 de dezembro de 1992 pelo Convênio ICMS 80/91; prorrogado até 31 de dezembro de 1993 pelo Convênio ICMS 1480/92; prorrogado até 30 de abril de 1995 pelo Convênio ICMS 124/93.

47. Lista Oficial das Espécies da Flora Brasileira Ameaçadas de Extinção, Portaria 6 de 23 de setembro de 2008, Diário Oficial da União de 24 de setembro de 2008, edição 185 , seção 1, p. 75-83.

48. Oltramari, A. C.; Silva, J. M. O. D.; Pedrotti, E. L.; Maraschin, M.; Rev. Árvore 2002, 26, 99.

49. Seabra, A. N.; Bol. Inst. Óleos 1958, 273.

50. Alencar, R.; Lima, R. A.; Correa, R. G. C.; Gottlieb, O. R.; Marx, M. C.; Silva, M. L.; Maia, J. G. S.; Magalhães, M. T.; Assumpção, R. M. V.; Acta Amaz. 1971, 1, 41; Gottlieb, O. R.; Koketsu, M.; Magalhães, M. T.; Maia, J. G. S.; Mendes, P. H.; Rocha, A. I.; Silva, M. L.; Acta Amaz. 1981, 11, 143.

51. Maia, J. G. S.; Silva, M. L.; Luz, A. I. R.; Zoghbi, M. G. B.; Ramos, L. S.; Quim. Nova 1987, 10, 200

52. Silva-Santos, A.; Antunes, A. M. S.; Bizzo, H. R.; d'Avila, L. A.; SouzaSantos, L. C.; Perf. Flavor. 2005, 30, 62.

53. Pimentel, F. A.; Rocha Neto, O., orgs.; Anais do Workshop de Encerramento do Projeto de Desenvolvimento de Tecnologias para Produção de Safrol a partir de Pimenta Longa (Piper hispidinervum), Embrapa Acre: Rio Branco, 2001.

54. Deschamps, C.; Zanatta, J. L.; Bizzo, H. R.; Oliveira, M. C.; Roswalka, L. C.; Ciênc. Agrotec. 2008, 32, 725. 